\title{
An Analysis of English News Reports from the Perspective of Graduation
}

\author{
Congcong Fan \\ Shanxi Normal University, Linfen, China
}

\begin{abstract}
As we all know, News is the main way to convey information, so the news reports should be fair, objective and neutral. Any newspaper and magazine serve the specific classes and groups, thus its reports necessarily reflect certain attitudes and positions. Based on Martin's Appraisal Theory, this paper analyzes ten news reports from China Daily from the perspective of Graduation. Graduation is a sub-system of Appraisal Theory. Its function is to adjust the attitude and the intensity of intervention, focusing on the typicality of the category. This article aims to reveal the ideology hidden behind objective words and the function of naturalizing value positions, which can help readers to improve their critical reading consciousness.
\end{abstract}

Index Terms - appraisal theory, graduation, stance, China daily

\section{INTRODUCTION}

In our daily life, we know everything from the news. In recent years, news has been the focus of the research. The characteristics of news reports are to speak with facts and report on objective things. And the content reflected in the news must convey the facts. However, the facts are not the news itself. The news reported is formed by the reporter's subjective reflection of objective facts. Moreover, any news report necessarily reflects the particular ideology. To some extent, although news reports require objectivity and fairness, there are few news reports which are absolutely objective. Therefore, when we read the news, we need to have critical thinking and find hidden meaning behind objective words rather than simply accept the information showed by the author. In the process of reading, we should try to comprehend the information standing in the position of the author. This paper will analyze ten pieces of news from China Daily from the perspective of graduation. Through analysis, the paper will help readers understand the intention of reporters better.

\section{LITERATURE REVIEW}

This part begins with an introduction of studies on Appraisal Theory abroad and at home. And then there is a description of the study of news report.

\section{A. Studies on Appraisal Theory}

There are a lot of researches about Appraisal Theory, which are mainly divided into the study of the theory itself and the application of the theory. In this part, the origin, the history and the development of Appraisal Theory will be reviewed in detail.

1. Studies on appraisal theory abroad

As a newborn theory, Appraisal Theory derives from Halliday's representative linguistic framework Systemic-Functional Grammar. Halliday (1994) stated in his book that people daily communication contained ideational, interpersonal and textual meaning. And the well-known interpersonal meaning is the origin of Appraisal Theory.

The birth of Appraisal Theory should date back to the early 1990s during a research project entitled Write It Right, which studied language level of students aged from eleven to eighteen. With the research going on, Martin and other researchers gradually shifted their attention from the study of narrative texts to the appraisal of literary criticism, media, history, science and technology. Since then, Martin has focused on the study of Appraisal Theory.

In 1992, English Text System and Structure was shaped and published by Martin, which firstly introduced the basic information of Appraisal Theory.

In 2000, Martin gave birth to a book named Beyond Exchange: Appraisal System in English. The early publications about Appraisal Theory have made a remarkable influence on people who devoted themselves to linguistic study. In the research, deeply influenced by Halliday's Systemic-Functional Grammar and driven by the spirit of innovation, Martin desired to combine the Systemic-Functional Grammar with discourse analysis organically. However, with the deepening of the research, Martin found that interpersonal function within Systemic-Functional Grammar was about the interaction between tone and modality in clause instead of the speaker's feeling. Therefore, in order to make up for the shortcomings, Martin, White and other scholars made great sacrifices and studied constantly. Eventually, The Language of Evaluation: Appraisal in English was generated as the complement of the shortcomings in 2005, which marked the climax of the Appraisal Theory. Martin's Appraisal Theory is consistent with Halliday's Systemic-Functional Grammar. It merely levels the interpersonal meaning in the communication process up to a different layer and appraises the 
discourse by the speakers' judgment and appreciation (Zhu Yongsheng, YanShiqing, 2011).

2. Studies on appraisal theory at home

Appraisal Theory has developed fast in China since it was first introduced by Wang Zhenhua. Wang Zhenhua (2001) published the article Appraisal Theory and its operation, introducing the background of the theory and explaining its theoretical framework and the specific operation.

In discourse analysis, Li Zhanzi (2004) generalized the application of Appraisal theory in analyzing commercial, historical and autobiographical discourse and also studied the interpersonal aspect of attitudes, the classification of interpersonal and ideational meaning, and discussed the relationship between Appraisal Theory and genres. Tang Liping (2009) studied the rhetorical categories and discourse strategies of the academic reviews by applying the Appraisal analysis and she also began to adopt the Appraisal Theory to explore the social construction function.

In the field of second language teaching and learning, Chen Shufang (2002) adopted the Appraisal theory in the vocabulary acquisition and believed the application of Appraisal Theory will help students solve many problems in vocabulary studying.

In media language research, Liu Shizhu (2004) and Han Jinlong (2004) discussed Appraisal Theory and its functions in news discourse and proposed the evaluative reading.

In the field of literary translation, Shan Huifang and Ding Suping (2006) analyzed the typical fairy tale-the Ugly Duckling from the perspective of Appraisal Theory and found that it held great explanatory power in the literary work.

Therefore, the range of application of Appraisal theory has been expanded. It has been applied to different genres by researchers abroad and at home, which provided a new way of discourse analysis from a different perspective. Until now, few attempts have been made to apply Appraisal Theory to the analysis of official statement, so the paper provides a new view to the analysis of official statement, which will also help the readers have a deeper understanding of official statement.

\section{B. The Study of News Report}

Appraisal Theory is a new development of interpersonal function of Systemic-Functional Grammar, which focuses on language expressions closely related to values. And it is conducive to reveal the ideology. There are some researchers abroad and at home who study the news discourses using Appraisal Theory. White (1998) tried to seek out the rhetorical potential of the news stories, showing the different systematic favoring and disfavoring of values of reporter voices and writer voices. Wang Zhenhua (2001) distinguished the attitude of the objective news between English and Chinese from the perspective of attitude resource. He pointed out that although objective news emphasized objectivity and fairness, the news writers should try to show their attitudes, positions, and opinions in a hidden way. Zheng Qun and Zhai Xia (2010), from the perspective of attitude, engagement and graduation resource, analyzed the news about the earthquake in Yushu reported in China Daily and New York Times. They concluded that the stance of the reporter was showed by three subsystems. Korner (2000) used Appraisal Theory to analyze the court trial words. Qian Hao (2008) examined the attitude meaning of discourse from the perspective of graduation, and proposed three parameters of attitude value-semantic, syntactic and context parameters.

Appraisal Theory has been a new perspective in news report. Therefore, the author will reveal the hidden meaning of news in terms of graduation system.

\section{THEORETICAL FRAMEWORK}

\section{A. Introduction of Appraisal Theory}

The Appraisal Theory is a theoretical system created by Martin, White and others in the 1990s, which derives from Halliday's Systematic-Functional Grammar and further complements the interpersonal function. There are three subsystems of Appraisal Theory, which are listed as Attitude system, Engagement system and Graduation system. Attitude system is a concentrated expression of the speaker's emotion, which involves the real reaction of people's emotions, the judgment of behavior and the evaluation of the aesthetic phenomenon. Accordingly, Attitude system includes Affect resource, Judgment resource and Appreciation resource. Engagement system deals with how the writers and readers share the same texts. Specifically, engagement involves ways like "quoting, reporting, acknowledging a possibility, denying, countering, affirming and so on" (Martin \& White, 2005, p 36). And it can be further divided into mono-gloss and hetero-gloss according to the different choices of speech strategies applied in different opinions. Graduation system refers to the power of the discourse, so it runs through the entire discourse. Force resource and Focus resource are included in this system. The former evaluates how powerful or reliable the discourse is, and the latter evaluates how clear or fuzzy the discourse is.

\section{B. Subsystems of Appraisal Theory}

There are three subsystems in the theory. They will be explained respectively in detail in this part.

1. Attitude system

As a central part of Appraisal Theory, attitude refers to people's reaction towards a heap of things in the mental process, such as behavior, text, phenomenon and so on. This system is divided into three sub-categories: affect resource, judgement resource and appreciation resource. Attitude system evaluates emotions and behavior of the character, and 
the value of things. What's more, whether it is the positive evaluation or negative evaluation, both of them can be identified according to the behavior of the participant under this system.

2. Engagement system

Engagement System is another part of Appraisal Theory. It is a system in which language resources are made up of a discourse or the source of speaker's voice. Mono-gloss and Hetero-gloss are used to express ideas, clarify opinions and positions. Mono-gloss with the character of speaking to oneself merely provides a kind of speaking position and does not acknowledge the existence of other positions. Hetero-gloss with the character of interlocutory, clearly indicates the possibility of another opinion, so Martin divides it into two sub-categories: contraction and expansion.

3. Graduation system

Graduation with the literal meaning of grading, is not limited to a particular area, but the entire Appraisal Theory system. Martin and White (2005) also believed that graduation was the center of the overall system. Graduation consists of two parts: force and focus. Force is about the degree of evaluation of the intensity and quality. Focus is about sharpening and softening of words which are applied in the most category. Both of them have a certain subsystem. In the fourth part the graduation will be explained in detail.

\section{THE APPLICATION OF GRADUATION}

\section{A. Force}

The force includes both intensification and quantification. Quality and process are in the category of intensification and the number, volume and span of entities are judged in the quantitative category. Intensification can be achieved through isolation, infusion, repetition (Martin \& White, 2005). Isolation is to up-scale or down-scale strength. For example, a bit, somewhat, relatively and so on, while infusion shows the function through the semantic of words, for example, contended, happy, joyous and so on. Repetition refers to repeating the same lexical locution or listing a group of locution that are semantically similar to one another. For example, we laughed and laughed and laughed (Martin \& White, 2005).

1. Intensification

Assessments of degree of intensity can operate over qualities (slightly foolish, extremely foolish), over processes (This slightly hindered us, This great hindered us), or over the verbal modalities of likelihood, inclination and obligation (it's just possible that, it's very possible that).We employ the term "intensification" to refer to this scaling of qualities and processes. (Martin \& White, 2008). The followings will show the application of theory in news.

a. Chinese courts have been ordered to offer more efficient legal services for litigants, with the nation's top court listing clearer responsibilities for court presidents and chief judges to prevent abuse of power in handling cases. On Wednesday, the Supreme People's Court, China's top court, issued a guideline on judicial reform for the next five years that said courts nationwide should make better use of technologies, including big data and artificial intelligence, to serve litigants...(China Daily, 2019/02/27)

The example uses the words "more efficient" "clearer" "better" which use comparative degree to show the intensification of quality. And they show the up-scale intensity by means of isolation, which can convey the hidden meaning of the news. Courts will be more efficient and fair using more technologies. This kind of expression can convey the positivity to readers and make the judgement more fair, as well as serve litigants in a better way.

b. "...On the basis of the latest progress, the two sides are expected to continue their work into the next stage, in accordance with the instructions of the two countries' top leaders, according to Xinhua. State Councilor Wang Yi said Sino-US trade negotiations have once again made concrete progress and provided positive prospects for bilateral relations and the global economy. Wang, also minister of foreign affairs, made the remark at an event on Monday, according to a statement issued by the ministry." (China Daily, 2019/02/26)

The example uses two words "concrete" "positive" which shows the intensification of quality. They embody the infusion of intensification and can express the attitude of the reporter. At the same time, they express the improvement of the relationship between China and the US on the basis of the latest progress. Besides, it is beneficial to the global economy. This kind of positive trend of relationship suits for the topic of peace. To a large extent, this expression can strike a chord between the author and readers.

c. ".......Following the top leaders' meeting, economic and trade teams of both sides have intensified negotiations, following a clear schedule and road map, according to earlier media reports. At meetings between US and Chinese officials last week in Beijing, the two sides "earnestly implemented" the consensus reached by the two heads of state during their Argentina meeting, and had in-depth communication on topics of mutual concern, according to a statement released by the Chinese side." (China Daily, 2019/02/22)

In the news, the word "earnestly" shows the intensification of quality. It shows the infusion of intensification. The sentence also expresses that both China and the US are eager to cooperate with the other. And they have an agreement on trade and economy. At the same time, the words embody the isolation of intensification to show their mood of being eager to implement the consensus. This usage of graduation expresses clearly that the relationship between them has made greater progress. Readers can make a good impression of the US and look forward to the world's peace.

d. Gary Hufbauer, a nonresident senior fellow of the Peterson Institute for International Economics, said the Chinese economic slowdown is partially due to the trade war, but more importantly, other factors, including a slowing world 
economy. "However, an escalation of the trade war will hit the US stock market hard, and that will contribute to a slowdown in the US economy," Hufbauer said. "President Trump needs a strong economy to stand a chance for re-election in 2020. His repeated suggestions that the US has the upper hand are wrong." (China Daily, 2019/01/23)

The example uses the word "repeated", which shows the intensification of the process. It modifies the noun "suggestion" and shows the isolation of intensification. His suggestion is that the US should not have the upper hand. In other words, the US should be friendly with China. They should cooperate with each other, which benefits the growth of the economy for both sides and the world. Cooperation is the only way to get better and makes contribution to people all around the world. Besides, the word can be easy to attract the readers and make them agree with the author.

e. "...Beijing and Washington have agreed to suspend any increase in tariffs after a meeting between President Xi Jinping and Trump on the sidelines of the G20 Summit in Buenos Aires, Argentina, on Dec 1. Days after the Argentina meeting, China's Ministry of Commerce had said that in 90 days, economic and trade teams of both sides would actively push forward the consultation following a clear schedule and road map."(China Daily, 2019/01/29)

The example uses the word "actively", which shows the intensification of the process. It modifies the verb "push forward" and shows the isolation of intensification. The news clearly expresses the idea that both China and the US will send a positive signal to their people and the international community, promote the sound development of bilateral ties and provide impetus to the steady growth of the global economy. And the better relationship between them is people's hope all around the world.

2. Quantification

Quantification is concerning the grade of amount and extent. It refers to the imprecise measuring of number, for example, a few miles, many miles and imprecise measuring of the presence or mass of entities according to such features as their size, weight, distribution or proximity, for instance, small amount, large amount, nearby mountain, distant mountain. (Martin \& White, 2008). The following is some news from China Daily.

a. ...The People's Republic of China and the United States formally established ties on Jan 1, 1979. Over the past four decades, the progress of China-US ties is nothing but staggering, far exceeding most people's expectations. Bilateral trade grew from a negligible $\$ 2.5$ billion in the late 1970 s to over $\$ 580$ billion in 2017 , while the stock of two-way investment rose from practically nil to more than $\$ 230$ billion. (China Daily, 2019/02/07)

The example uses the quantification. The news uses data to show the great improvement of the relationship between China and the US. The number from $\$ 2.5$ billion to $\$ 580$ billion shows the significant improvement. There is no doubt that new global challenges keep coming up and the world needs China and the United States to work together. What is more, people need the steady and peaceful community to have a higher quality of life. The number can convince the readers to be in keeping with the author. And peaceful coexistence is our common expectation.

b. HANGZHOU - Chinese e-commerce giant Alibaba created about 40.82 million jobs last year via its expansive retail ecosystem, up 10.9 percent year-on-year, a recent report showed. The company's various e-commerce platforms, including Taobao and Tmall, provided about 15.58 million jobs for online retailers in 2018, according to a report from Renmin University of China. Apparel and textiles, daily necessities and home appliances were the top three retail items that offered the most jobs. Alibaba's booming online retail service also helped boost demand for professionals in upstream and downstream sectors like R\&D, design, manufacturing and logistics, totaling about 25.24 million jobs. In a bid to help disadvantaged groups find jobs, the company provided training programs through its learning platform "Taobao University."'(China Daily, 2019/02/28)

The example uses the quantification. The news uses some data to show the influence of Alibaba. With the development of the technology, there are many people who go shopping on the Internet. Without doubt, it is easier for us to buy something. And it can help us save more time. At the same time, it makes that the express delivery industry has emerged increasingly. To some extent, it can decrease the rate of unemployment and help disadvantaged groups find jobs. As the data shows, it provides us with many jobs and the amount of the job shows an upward tendency. Alibaba have played an important role in stabilizing and boosting employment. The reporter uses the number, which can show the readers the improvement of the phenomenon in a clearer way. It can help readers to understand the news quickly.

c. KUNMING - Yunnan, a border province in Southwest China, saw its foreign trade rise 35.8 percent year-on-year to 19.9 billion yuan ( $\$ 3$ billion) in January, said Kunming Customs Thursday. Trade with countries involved in the Belt and Road Initiative accounted for about 70 percent of the total, with the value increasing by 18.7 percent to 13.9 billion yuan, the customs said. Exports of machinery and electrical equipment surged 87.1 percent to 2.8 billion yuan, while exports of agricultural products jumped 49.5 percent to 2.3 billion yuan. Despite robust growth in the broader trade, Yunnan witnessed a decline in imports of crude oil and natural gas. The province imported 812,000 metric tons of crude oil and 315,000 tons of natural gas in January, down 8.7 percent and 2 percent, respectively.(China Daily, 2019/02/28)

The example uses the quantification. Some data means that the border province in southwest China has a great amount of trade with foreign countries. The export of electrical equipment and agricultural products shows an upgrade trend. Therefore we can know that we have produced more advanced machines and we have made great progress in the agriculture. And in the last sentence, the import of the oil has a downgrade tendency. The phenomenon shows that we can satisfy our need by ourselves. There is no doubt that our country has great promotion than before. The characteristic of the news is to show the change of economy of our country. It can easily persuade readers by means of data.

\section{B. Focus}


According to Martin \& White, the focus resource is "scaled by reference to the degree to which they match some supposed core or exemplary instance of a semantic category" (Martin \& White, 2005, p. 137). It is possible to up-scale or sharpen the specification so that prototypicality is indicated, for example, a real father, a true friend or to down-scale, or soften the specification so as to characterize an instance as having only marginal membership in the category, for instance, they sort of play jazz, they are kind of crazy, it was an apology of sorts. The followings are corresponding examples.

1. Earlier on Thursday, Trump tweeted, "China's representatives and I are trying to do a complete deal, leaving NOTHING unresolved on the table. All of the many problems are being discussed and will be hopefully resolved."

"No final deal will be made until my friend President Xi and I meet in the near future to discuss and agree on some of the long-standing and more difficult points," he wrote on he wrote on his Twitter account. "We haven't set up a meeting yet," Trump told reporters, according to a White House transcript. "I think we're working on seeing where everybody is, and then we'll meet to discuss some final issues." Trump added that "both countries would like to see a positive result". (China Daily, 2019/02/02)

The example uses the focus. The word "some of" shows the soften tone, which can be accepted by others. There are some difficult points to be resolved between them. And they will be discussed and hopefully solved in the future. It shows a positive result which can appeal to readers to agree on the idea easily. At the same time, it can convey the positiveness to us.

2. China should be prepared to fight a protracted and tough battle against financial risks, said a senior official of the country's top banking and insurance regulator. "We have made progressive achievements in preventing and defusing financial risks, but many potential risks are not fully eliminated yet and our previous accomplishments in risk mitigation still need to be consolidated," Wang Zhaoxing, vice-chairman of the China Banking and Insurance Regulatory Commission, said at a news conference on Monday. (China Daily, 2019/02/26)

The example uses focus. The word is "fully" used to up-scale or sharpen the specification so that prototypicality is indicated. It also shows the extent and means that at present, we still have some potential risks which are not eliminated. Although we have made great progressive achievements in preventing financial risks, we must fight against the potential risks.

\section{CONCLUSION}

The use of the graduation is extremely common in news reports. As a sub-system of Appraisal Theory, the graduation mainly plays a crucial role in the discourse, which is to naturalize the author's attitude and position, and at the same time naturalize the readers' position, aiming at constructing readers. To some extent, it can help to reveal the deeper meaning of the news. However, the author mainly analyses the news discourse using Graduation resource without the consideration of Attitude resource and Engagement resource. In terms of research methods, most of the previous studies use small-scale corpus for analysis, so we should enlarge corpus to improve the reliability. What's more, there are large research spaces for topics such as discourse usage patterns and genre differences. Therefore, we should take further study in the future.

\section{REFERENCES}

[1] Chen Shufang. (2002). Appraisal System and Lexical Production. Shandong Foreign Language Teaching. 6, 28-30.

[2] Halliday, M.A.K. (1994). An introduction to functional grammar. London: Edward Arnold.

[3] Korner, K. (2000). Negotiating Authority: The Logogenesis of Dialogue in Common Law Judgment. Sydney: University of Sydney.

[4] Li Zhanzi. (2004). Appraisal Theory: Applications and Problems in Discourse Analysis. Foreign Language Studies. 5, 1-7.

[5] Liu shizhu \& Han Jinlong. (2004). Appraisal System in News Discourse. Technology Enhanced Foreign Language Education, 4, 17-21.

[6] Martin, J. R. (1992). English text: System and structure. Philadelphia, PA/Amsterdam: John Benjamins.

[7] Martin, J. R. \& P. R. R. White. (2005). The Language of Evaluation: Appraisal in English. London: Palgrave.

[8] Martin, J. R. \& White, P.R.R. (2008). The Language of Evaluation: Appraisal in English. Beijing: Foreign Language Teaching and Research Press.

[9] Martin, J. R. (2000). Beyond exchange: Appraisal systems in English. In S. Hunston \& G. Thompson (Eds). Evaluation in Text Authorial Stance and the Construction of Discourse. Oxford: Oxford University Press, 93-94.

[10] Qian Hao (2008). Attitude Meaning of Discourse from the Perspective of Graduation--A Parametric Analysis of Attitude Value. Exam Weekly, 53, 135-137.

[11] Shan Huifang \& Ding Suping. (2006). the Analysis of The Ugly Duckling from the perspective of Appraisal Theory. Journal of Xi'an Foreign Studies University. 3, 14-17.

[12] Tang Liping. (2009). Critical Discourse Analysis of English Learners' Interpretation of Cultural Hegemonic Discourse. Journal of PLA University of Foreign Languages. 4, 47-51.

[13] White, P. R. R. (1998). Telling Media Tales: The News Story as Rhetoric. Sydney: University Sydney Press.

[14] Wang Zhenhua. (2001). Appraisal Theory and its operation-new development of Systemic Functional Linguistics. Foreign Language (Journal of Shanghai International Studies University). 6, 13-20.

[15] Zhu Yongsheng \& Yan Shiqing. (2011). New Reflections on Systemic Functional Linguistics. Shanghai: Fudan University Press. 
[16] Zheng Qun \& Zhai Xia. (2010). An analysis of the "hard news" position from the perspective of evaluation theory. Journal of Shanxi Normal University. 37, 91-93.

Congcong Fan, was born in Linfen, Shanxi, China in 1993. She is studying for Master's Degree in Foreign Linguistics and Applied Linguistics in Shanxi Normal University, China. 